\title{
Direct phloem transport and pressure concentration waves in linking shoot and rhizosphere activity.
}

\author{
Olga Gavrichkova • Yakov Kuzyakov
}

Received: 18 February 2011 /Accepted: 8 July 2011 /Published online: 20 August 2011

(C) The Author(s) 2011. This article is published with open access at Springerlink.com

\begin{abstract}
Background Two recent reviews raised a fundamental question: what is the time lag between photosynthetic $\mathrm{C}$ uptake and $\mathrm{CO}_{2}$ efflux from soil. Both reviews, however, in describing the linkages between $\mathrm{CO}_{2}$ assimilation and $\mathrm{CO}_{2}$ efflux from soil, were unable to evaluate the significance of two mechanisms i) the direct transport of assimilates to the roots and rhizosphere and ii) phloem pressure concentration waves. This uncertainty led to a further discussion about the suitability of labeling when evaluating time lags.

Scope Here, we estimated the importance of the direct transport of assimilates to the rhizosphere and the importance of phloem pressure concentration waves by various approaches, and reveal further differences between both reviews.

Conclusions We show that the pressure concentration waves only briefly play a role for $\mathrm{CO}_{2}$ efflux. In contrast, the direct transport influence lasts longer and
\end{abstract}

Responsible Editor: Katja Klumpp.

O. Gavrichkova $(\bowtie)$

CNR, Institute of Agro-Environmental

and Forest Biology (IBAF),

38050 Cinte Tesino, Italy

e-mail: olga.gavrichkova@ibaf.cnr.it

\section{Y. Kuzyakov}

Department of Soil Science of Temperate Ecosystems, University of Göttingen,

37077 Göttingen, Germany

e-mail:kuzyakov@uni-goettingen.de so, it is more important for rhizosphere processes and for $\mathrm{CO}_{2}$ efflux. To evaluate the significance of these two mechanisms, we suggested a new approach based on regressions between the time lag and tree height, which confirms significance of pressure concentration waves only for trees, smaller than $2.5 \mathrm{~m}$.

Keywords Canopy-rhizosphere coupling · Labeling approach · Phloem transport - Soil respiration .

Pressure concentration waves - Regression analysis . $\mathrm{CO}_{2}$ partitioning

\section{Introduction}

Two recent reviews showed a very close link between assimilation of $\mathrm{CO}_{2}$ from the atmosphere by plants and $\mathrm{CO}_{2}$ efflux from soil (Mencuccini and Hölttä 2010a; Kuzyakov and Gavrichkova 2010). The link was not considered in most previous studies, and most changes in the $\mathrm{CO}_{2}$ efflux from soil were attributed to temperature variations. These reviews therefore provided new insights into the traditional concepts of connection between above- and belowground processes.

Both review initially had different aims: Kuzyakov and Gavrichkova (2010) - to emphasize the dependence of $\mathrm{C}$ turnover in soil and in particular root/rhizosphere respiration on plant photosynthetic activity and Mencuccini and Hölttä (2010a) — to test the hypothesis of the faster communication between plant photosynthetic status and root metabolism than that through the direct transport of assimilated molecules with phloem 
flow. Two mechanisms behind the link between $\mathrm{CO}_{2}$ assimilation and $\mathrm{C}$ release in the rhizosphere were described in the reviews: 1) direct phloem transport of assimilates from the leaves through the shoots or trunk to the roots, and 2) C release induced by phloem pressure concentration waves (Fig. 2 in Kuzyakov and Gavrichkova 2010). The approaches allowing estimation of the time lag between $\mathrm{CO}_{2}$ assimilation and $\mathrm{C}$ release in the rhizosphere were described in detail, also with regard to the possibility of evaluating the two mentioned mechanisms in linking plant above- and belowground compartments. Both reviews stimulated the further discussion (see Letters: Kayler et al. 2010; Mencuccini and Hölttä 2010b) concerning the possible contribution of both mechanisms: direct assimilate transport and pressure concentration waves, to belowground $\mathrm{C}$ input. The suitability of the isotope labeling approach for the detection of the effect of rapid changes in photosynthesis on the substrate availability for roots and thus on the rates of $\mathrm{CO}_{2}$ efflux from soil was questioned. It is important to emphasize that the conclusions driven by both reviews on the applicability of isotope-based labeling approach for time lag detection do not contradict to each other, as it could seem on the first glance following the letters of Kayler et al. (2010) and Mencuccini and Hölttä (2010b). In fact, Kuzyakov and Gavrichkova (2010) (see table S1, in Kuzyakov and Gavrichkova 2010) stated that labeling approach is not able to evaluate the effect of pressure concentration wave's propagation on soil respiration if the last takes place. Mencuccini and Hölttä (2010a) concluded actually the same, not detracting the importance of isotopic approach in tracing the fate of the direct $\mathrm{C}$ molecules in plant-soil compartment, in determination of the residence time of $\mathrm{C}$ in pools and fluxes and its allocation patterns.

The main question which actually remains open in both reviews is how important is the influence of the propagation of pressure concentration waves, if present, on root metabolism and rhizosphere respiration? Could it affect soil respiration to the grade that the time lag between $\mathrm{C}$ assimilation and its following respiration from rhizosphere measured by isotopic approaches become non representative in describing the speed of link between aboveground and belowground activity? In the last case, the term "speed of link" when referred to isotope studies will become meaningless.

Here, we a) make an attempt to estimate the relative contribution of direct transport and pressure concentra- tion waves to the $\mathrm{C}$ input into the soil, b) suggest a new approach based on regressions between the time lag and tree height and c) show the differences in the statistical evaluation of original data to the time lag conducted in both reviews. The first two efforts help to evaluate the importance of both mechanisms and to objectively examine the labeling approach for time lag evaluation. The third effort explains some differences in the conclusions drawn in the two reviews concerning the duration of the time lag.

\section{Why is disentangling the direct transport and pressure concentration waves necessary?}

The necessity for separating the two mechanisms reflects the different time in the response of roots and rhizosphere microorganisms to changes in plant photosynthetic activity depending on which mechanism is actually active and dominating. An increase in the turgor pressure is created in one loading phloem end by an increase in photoassimilate production and export rates. This results in the pressure propagation throughout the phloem and expulsion of the sucrose molecules from the phloem opposed end (Mencuccini and Hölttä 2010b). The possible consequence is an increase in the availability of sugars to sustain root and rhizomicrobial metabolism within a much shorter time frame than direct molecule transport. In contrast, the direct transport of assimilates belowground requires much more time: on average about $12 \mathrm{~h}$ for grasses and at least a few days for trees (Kuzyakov and Gavrichkova 2010). What has been neglected to date is that the effect of pressure propagation on the amount of evolved $\mathrm{CO}_{2}$ would be relevant only if the quantity of sugars released into roots and rhizosphere is comparable with the quantity of sugars transported directly. Moreover, the response period of root and rhizosphere to $\mathrm{C}$ supplied through two mechanisms could differ. As the environmental drivers of both mechanisms are at least partly different, it is crucial to evaluate the possible contribution of both mechanisms to the belowground $\mathrm{C}$ input.

\section{To what degree can the pressure concentration waves affect the $\mathrm{CO}_{2}$ efflux from soil?}

The impact of photosynthesis rate on $\mathrm{CO}_{2}$ efflux from soil through changes in the quantity of the directly 
transported molecules is easy to measure through detecting of artificial or natural tracers in respired $\mathrm{CO}_{2}$. Conversely, the impact of photosynthesis through propagation of pressure waves is hard to estimate as not the same molecules are released from roots. An indirect evidence of wave's propagation impact on root metabolism could be shorter time lags between photosynthesis and soil/root respiration measured with flux-based approach (Mencuccini and Hölttä 2010a). The amount of $\mathrm{C}$ released through pressure propagation is however not possible to assess with such techniques. In this Letter we aimed to roughly estimate the contribution of pressure concentration waves to the $\mathrm{CO}_{2}$ efflux from soil. Such an estimation requires the following information: a) concentration of transported sugars (since the amount of other transported organics is negligible in most plant species) in the phloem, especially in the phloem of roots; b) changes of water volume in the phloem by sugar loading. The product of the concentration and released solution volume should roughly reflect the amount of organic $\mathrm{C}$ released by pressure concentration waves and is the upper estimation of their contribution to the $\mathrm{CO}_{2}$ efflux from soil.

The first parameter, concentration of the phloem sap, is usually measured at a breast height. Sucrose was often found to be the main component of the transported solution (Peuke et al. 2001; van Bel 2003; Scartazza et al. 2004). The sucrose concentration in the phloem of Ricinus was in the range of 400 $500 \mathrm{mmol}$ (Peuke et al. 2001); in beech trees the values were $200-1000 \mathrm{mmol}$ (Keitel et al. 2003) or 200-400 mmol (Gessler et al. 2001), in eucalyptus trees 500-800 mmol (Cernusak et al. 2003). Daynight changes in the sucrose concentration in the phloem sap were observed in several experiments, with characteristic night decrease induced by declining sugars loading rates (Grimmer and Komor 1999; Komor 2000; Peuke et al. 2001; Göttlicher et al. 2006 (sugars in leaves)).

Increase in the turgor pressure in response to sugar loading is initially localized in a small volume of the phloem vessels in leaves. Turgor changes within this small volume should then be equilibrated by the water volume in the whole phloem, resulting in phloem solution expulsion on the opposed end (Mencuccini and Hölttä 2010b). Let us use the tree characteristics suggested in Tables 2 and 1 by Mencuccini and Hölttä (2010a) and Hölttä et al. (2009), respectively and assume the rapid changes in photosynthesis like night-to-day transition, when plant goes through zero to maximum photosynthetic rate. The tree characteristics are: a) height of $10 \mathrm{~m}, \mathrm{~b}$ ) phloem cross section area of $1.3 \cdot 10^{-3} \mathrm{~m}^{2}$, not changing with height, and $\mathrm{c}$ ) tree leaf area of $50 \mathrm{~m}^{2}$. Taking the average photosynthesis rate at $10 \mu \mathrm{mol} \mathrm{C} \mathrm{m}{ }^{-2} \mathrm{~s}^{-1}$, and assuming that half of the assimilated $\mathrm{C}$ is exported via phloem (Grodzinski et al. 1998; Grimmer and Komor 1999), the phloem loading is about $250 \mu \mathrm{mol} \mathrm{C} \mathrm{s}{ }^{-1}$. This corresponds to a sucrose loading rate of around $20.8 \mu \mathrm{mol} \mathrm{s}^{-1}$. The sucrose is loaded in the upper phloem end, let us assume in the first $0.3 \mathrm{~m}$ (similar to Hölttä et al. 2009), so that the affected phloem volume is $390 \mathrm{ml}$. Taking a sucrose concentration at the base trunk of $200 \mathrm{mmol}$ (minimum early morning rates) and a concentration gradient along the trunk of 0.01 mol per meter (Zimmermann 1960), the expected phloem sap concentration on the top phloem end is $300 \mathrm{mmol}$, and $190 \mathrm{mmol}$ on the opposed end in the roots. As the solutes are pushed into the phloem and the osmotic potential rapidly decreases, water inflows passively, increasing turgor, until the new steady state with the loading rate is reached. Approximately $0.07 \mathrm{ml} \mathrm{s}^{-1}$ of water per plant should enter into the phloem to re-equilibrate osmotic changes. Increased turgor will push the solution downward. Assuming further constant phloem volume, the same amount of water will be released on the opposed phloem end by propagation of the created pressure wave (Mencuccini and Hölttä 2010b). Thus, the simultaneous efflux of water from the unloading phloem would be $0.07 \mathrm{ml} \mathrm{s}^{-1}$, and the amount of sucrose released with this water volume, taking into account the abovementioned concentrations, corresponds to $4.5 \mathrm{mg}$ sucrose $\mathrm{s}^{-1}$ per tree. This is equivalent to $1.9 \mathrm{mg} \mathrm{C} \mathrm{s}^{-1}$ and reflects the maximal flux of $\mathrm{C}$ released within one pressure concentration wave at the current loading rate. The expelled $\mathrm{C}$ will be used to support various processes such as root growth, ion uptake, maintenance respiration and symbiotic relations. However, the quantity of water pulsed into the phloem is probably not proportional to the osmotic potential increase at a certain level of loading rates. This is because it is restricted by the cell wall elasticity and elasticity of phloem volume that is supported by diurnal variation in sucrose concentrations in the phloem. Accordingly, the reported water influx rate is the maximum possible at a current sugar loading. 
When evaluating the significance of the phloem pressure concentration waves, it is also important to estimate their duration. Photosynthesis increases within a few minutes after light increases and remains relatively constant thereafter. Consequently, the duration of the $\mathrm{C}$ release in the rhizosphere within such a pressure concentration wave should be quite short. The osmotic pressure initiated by the increased sucrose concentration will be compensated by the water influx and a new steady state with photosynthesis and loading rate will be reached. Correspondingly, if no particular changes in photosynthetic rate after its initial rise occur, the expected quantity of $\mathrm{C}$ released with the pressure concentration wave amounts to several mg C per plant per hour.

Upper phloem turgor changes propagation to roots as shown by Mencuccini and Hölttä (2010b) is however not immediate, and in their example it took almost $7 \mathrm{~h}$ for the pressure wave to transmit belowground, whereas molecules transported with the bulk flow reached roots about $90 \mathrm{~h}$ later.

In such a modeled simplified system it is possible to imagine the wave's creation and transmission. In a complex plant system, however, numerous factors would interact on different temporal and spatial scales, possibly also quenching the wave's propagation. Such factors could include 1) timing of metabolite build-up, 2) diurnal variation of xylem volume with consequences for the phloem volume, 3 ) variation of phloem volume throughout the trunk, 4) continuous exchange of sugars and water between phloem and surrounding tissues along the trunk, 5) sink-induced regulations, 6) net flow of water from xylem as the more concentrated solution moves down and others.

\section{Contribution of direct transport}

The quantity of recently assimilated C, directly translocated by the phloem mass flow to roots and soil, was estimated in many ${ }^{14} \mathrm{C}$ or ${ }^{13} \mathrm{C}$ labeling studies. Allocated to belowground $\mathrm{C}$ is further distributed between various pools and fluxes: formation of root biomass, storage, root exudation and respiration (Werth and Kuzyakov 2008). In trees, the percentage of recently assimilated label allocated into the rhizosphere and released from soil as root respiration and microbial respiration varies from $5 \%$ to $15 \%$ of total assimilated label (Horwath et al. 1994; Phillips and Fahey 2005; Plain et al. 2009). The corresponding values for grasses and herbs range from $1 \%$ to $43 \%$ (e.g. Wu et al. 2010; Kuzyakov and Domanski 2000 for review). Most of this $\mathrm{C}$ is respired from roots and the rhizosphere during a very brief period, as reflected in the ${ }^{14} \mathrm{CO}_{2}$ or ${ }^{13} \mathrm{CO}_{2}$ evolution peaks in pulse labeling experiments (Nguyen et al. 1999; Subke et al. 2009; Gavrichkova and Kuzyakov 2010). If we consider this $C$ partitioning (10\% of assimilates for root and rhizomicrobial $\mathrm{CO}_{2}$ ), and assume the above-reported photosynthesis of $10 \mu \mathrm{mol} \mathrm{C} \mathrm{m} \mathrm{m}^{-2}$ and a leaf area of $50 \mathrm{~m}^{2}$, then the $\mathrm{CO}_{2}$ respired by roots and rhizosphere microorganisms from soil will be about $50 \mu \mathrm{mol} \mathrm{C} \mathrm{s}{ }^{-1}$ per plant. This is actually the lower estimation of the rates of root-derived $\mathrm{CO}_{2}$ released in the rhizosphere of one tree.

At first glance this value $\left(50 \mu \mathrm{mol} \mathrm{C} \mathrm{s}^{-1}=\right.$ $0.6 \mathrm{mg} \mathrm{C} \mathrm{s}^{-1}$ ) is less than the $\mathrm{C}$ released by pressure concentration waves during the same period. Here, however, we neglect the $\mathrm{C}$ transported with phloem flow, which fuels processes other than respiration in roots and rhizosphere so that the final number should be closed to one reported for wave's transmission or exceed it. However, if no other particular variations in photosynthesis occur despite the night-to-day transit, the releases of $\mathrm{C}$ due to formation of pressure concentration wave to compensate the osmotic pressure initiated by phloem loading is relatively low on the whole day basis. In contrast, the direct transport leads to continuous $\mathrm{C}$ release in the rhizospheremany hours per day, and the rough calculation shows that the $\mathrm{C}$ flux per one hour will be already on the order of grams per tree. Therefore, despite the shortterm comparable rate of $\mathrm{C}$ released by direct phloem pressure concentration waves, their importance is more likely much less than that of direct transport on a long-term.

\section{Other differences in the conclusions of the two reviews}

Other discrepancies between the two reviews in the time lags measured by different experimental approaches reflect several differences in data preparation and statistical processing. It should be considered that the authors were approaching different 
objectives (see above); accordingly, the criteria for the data organization were also different between two reviews. For example, the pathway length of assimilated C was differently considered: Kuzyakov and Gavrichkova (2010) took into account only tree height. Together with the tree height, Mencuccini and Hölttä (2010a) also incorporated root depth. Additionally, Kuzyakov and Gavrichkova (2010) analyzed only studies in which plant height was effectively measured, whereas Mencuccini and Hölttä (2010a) probably estimated approximate tree and grass heights, even for the papers where these data were not explicitly reported. Therefore, the number of data for statistical analysis and points on graphs is different.

Methods for time lag evaluation were grouped also differently. Mencuccini and Hölttä (2010a) divided the data into two groups of approaches: flux-based and isotope-based. In contrast, Kuzyakov and Gavrichkova (2010) analyzed instead each sub-method separately: within flux-based group Interruption and time series analysis (TSA) approaches were taken and within the isotope-based group: ${ }^{13} \mathrm{C}$ natural abundance and artificial ${ }^{13} \mathrm{C}$ or ${ }^{14} \mathrm{C}$ labeling. Therefore, a larger data set in both groups by Mencuccini and Hölttä was created (2010a).

To emphasize the differences in phloem structure and physiology between herbaceous vegetation and trees these two groups were treated separately in the review of Kuzyakov and Gavrichkova (2010). Differences between trees and grasses in the time delay as a function of plant height were clearly shown in Figs. 5 and 6 in Kuzyakov and Gavrichkova (2010). This also changed the number of pairs used for statistical analysis in both reviews. We suggest additional separate treatment of two functional groupsangiosperms and gymnosperms - because they are different in phloem structure and show distinct differences in delay pattern at least in case of the direct molecule transport (Fig. 7 in Kuzyakov and Gavrichkova 2010).

\section{Estimation of the importance of phloem pressure concentration waves and direct transport based on regression lines}

The dependence of time lag on the tree height was significant only when pulse labeling was utilized for its evaluation. The correlation with the tree height was not significant for the time lags obtained by fluxbased, 13C natural abundance and interruption methods, so that analysis of variance was chosen for methods comparison (Fig. 6 in Kuzyakov and Gavrichkova 2010). It was, however, found that C translocation velocity $\left(\mathrm{m} \mathrm{h}^{-1}\right)$ depends on the length of the pathway (Mencuccini and Hölttä 2010a). This aspect was not considered in our review, making the statistical evaluation that considers the covariance of transfer times against height used by Mencuccini and Hölttä (2010a) more correct than the approach we utilized for the methods comparison. Therefore, in preparing this Letter, we have changed our statistical evaluation and used the same data set as in our previous paper but separation into three methods (Interruption was discarded due to lack of points and low frequency of sampling) and considering the covariance between time lag and plant height. We then compared the slope and the intercept of the regression between time lag and plant height obtained by different methods. We found no significant differences in slopes of the regression lines $(p=0.06)$ between the analyzed groups. The intercept, however, differed between all methods $(p=0.008)$. The slope reflects the duration of direct assimilate transport from the leaves to belowground, depending on tree height. The intercept, however, shows the time lag component that is independent of plant height. If the phloem pressure concentration waves significantly affect the time lag, then the regression line should cross the $\mathrm{X}$ axis at some plant height. This is because the time lag by pressure concentration waves is much shorter compared to direct mass flow transport, even though the plants may be tall.

To apply this new approach, we took the data of Fig. 5 from Kuzyakov and Gavrichkova (2010), reflecting the dependence of time lag on tree height. Flux-based approach for time lag determination is weakly presented in the literature, resulting in few points on the graph, especially for young trees with a short phloem path. We have added additional points which we didn't report previously. The sampling resolution is low in some of them (around $1 \mathrm{~d}$ ). While awaiting for more detailed experiments, we think that these points can give still relevant information, especially considering that the effect of the pressure propagation on root metabolism is also not immediate (Mencuccini and Hölttä 2010b). Additionally, the 
results of the labeling of the mature trees were added to the labeling approach data (Kuptz et al. 2011). We have calculated and confronted linear regressions for three approaches (Fig. 1): a) time series analysis of $\mathrm{CO}_{2}$ efflux (TSA of $\mathrm{CO}_{2}$ ), b) labeling, and c) natural $\delta^{13} \mathrm{C}$ variation of $\mathrm{CO}_{2}$ efflux from soil. The results allowed interesting conclusions: The intercept of linear regression for labeling $\left(R^{2}=0.58, p=0.006\right)$, which cannot evaluate pressure concentration waves, was positive and corresponds to a 1.8-day time delay $(p=0.002)$. In contrast, the linear regression for TSA of $\mathrm{CO}_{2}\left(R^{2}=0.29, p=0.05\right)$ showed a "negative time lag" for short trees, meaning a negative intercept (although, not significantly different from zero) (Fig. 1). This indicates that for trees of about $2.5 \mathrm{~m}$ height, there could be no time lag. Such a situation may take place if the response to increased photosynthesis is reflected in $\mathrm{CO}_{2}$ efflux from soil very fast,

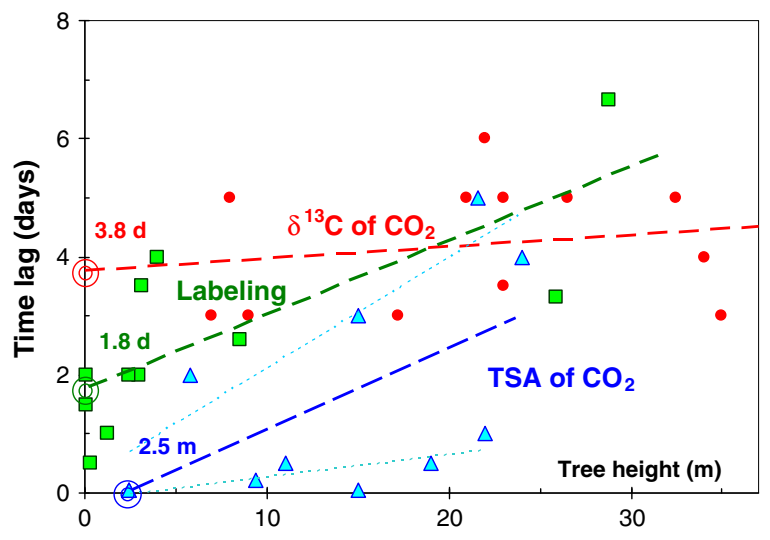

Fig. 1 Rough estimation of the importance of contribution of phloem concentration waves to the time lag between photosynthesis and $\mathrm{CO}_{2}$ efflux from soil based on the intercept with $\mathrm{Y}$ axis calculated by linear regression between the found time lags for increasing tree height. Positive $\mathrm{Y}$ intercepts estimated for Labeling (1.5 days) and $\delta^{13} \mathrm{C}$ of $\mathrm{CO}_{2}$ (3.8 days) shows time lag between $\mathrm{C}$ photoassimilation and $\mathrm{CO}_{2}$ efflux from soil estimated by these approaches. There is nearly no time lag by Time Series Analysis of $\mathrm{CO}_{2}$ (TSA of $\mathrm{CO}_{2}$ ) confirming fast response of soil $\mathrm{CO}_{2}$ on increased photoassimilation for small trees. Dotted regression lines correspond to visual subdivision of TSA of $\mathrm{CO}_{2}$ result into two subgroups. The data points from Kuzyakov and Gavrichkova (2010) were updated by Gärdenäs 2000 (plant height was determined from the regression line of tree height vs. age constructed from other available data, $3 \mathrm{~d}$ was accepted as a lag), Irvine et al. 2005; Hartley et al. 2006; Drake et al. 2008; Pumpanen et al. 2009 (personal communication on plants height at the time of labeling), Kuptz et al. 2011 (lag, averaged over the growing season) and thus only through the second mechanismpropagation of pressure concentration waves. No particular changes in statistical evaluation of differences in slopes and intercepts between methods respect to the previously used dataset were found. The relationships between plant height and time lag as well as between plant height and $\mathrm{C}$ translocation velocity $\left(\mathrm{m} \mathrm{h}^{-1}\right)$ obtained by TSA of $\mathrm{CO}_{2}$ were not significant and interestingly, two distinct patterns for plants higher than $2.5 \mathrm{~m}$ (Fig. 1) could be identified. The first one is characterized by steep increase of the time lag with height $\left(R^{2}=0.86, p=0.02\right)$, and the second one - with no dependence on the plant height and low slope $\left(R^{2}=0.57, p=0.08\right)$. These two patterns were independent on whether the gymnosperm or angiosperm plants were studied as in the case of the labeling approach. Analyses of covariance demonstrate both, different slope and intercept $(p<0.05$ and $p<0.01$ respectively), if we additionally separate TSA of $\mathrm{CO}_{2}$ into two subgroups and confront them with isotopic methods. It is worth to add that some studies from the second TSA subgroup have also reported longer lags (in order of weeks), which were not considered in either reviews. Studies from the first TSA subgroup in confront were mostly of the lower time resolution. Given this, we still cannot definitely exclude that a significant discrepancy in the time lag duration obtained by flux-based and labeling-based approaches is due to experimental set-up limitations (Kuzyakov and Gavrichkova 2010).

\section{Conclusions}

Both reviews and both previous Letters clearly concluded that the phloem is the 'bottleneck' for the time lag between photosynthesis of trees and various rhizosphere processes including $\mathrm{CO}_{2}$ efflux from soil. Despite some differences in the conclusions concerning the time lag estimated in the reviews by flux-based and isotope-based approaches, in this Letter we show that these differences are connected with the consideration of the a) root depth, b) approaches grouping, and c) statistical evaluation. Accordingly, the experimental data of previous studies would allow similar conclusions to be drawn by both reviews and thus remove the apparent discrepancies. However, the contribution of two mechanisms (phloem concentration waves vs. direct assimilate transport) to the linkage between 
photosynthesis and $\mathrm{CO}_{2}$ efflux from soil can be estimated only by considering the amounts of $\mathrm{C}$ transported to roots and released into the rhizosphere. Our theoretical estimation showed that, although the amount of soluble $\mathrm{C}$ that may be released by pressure concentration waves is significant, the short duration of this mechanism limits its importance for the contribution to the $\mathrm{CO}_{2}$ efflux from soil. In contrast, the amount of assimilates transported belowground directly is lower per time unit, but because of the much longer duration, this mechanism contributes significantly to the $\mathrm{CO}_{2}$ efflux from soil. Based on the intercept with $\mathrm{Y}$ axis calculated by linear regression between the time lag and tree height, we suggest a new approach for estimating the contribution of both mechanisms. Experimental studies are urgently needed to confirm or refute the formation and translocation of pressure concentration waves and, more importantly, to identify conditions in which such waves exert a significant influence on root and rhizomicrobial activity.

Acknowledgements The present work is part of "CARBOSOIL" project funded by the Autonomous Province of Trento (Italy) under "Marie Curie Action - COFUND PostDoc 2010 Incoming" programme.

Open Access This article is distributed under the terms of the Creative Commons Attribution Noncommercial License which permits any noncommercial use, distribution, and reproduction in any medium, provided the original author(s) and source are credited.

\section{References}

Cernusak LA, Arthur DJ, Pate JS, Farquhar GD (2003) Water relations link carbon and oxygen isotope discrimination to phloem sap sugar concentration in Eucalyptus globulus. Plant Physiol 131:1544-1554

Drake JE, Stoy PC, Jackson RB, DeLucia EH (2008) Fine-root respiration in a loblolly pine (Pinus taeda L.) forest exposed to elevated $\mathrm{CO}_{2}$ and $\mathrm{N}$ fertilization. Plant Cell Envir 31:1663-1672

Gärdenäs AI (2000) Soil respiration fluxes measured along a hydrological gradient in a Norway spruce stand in south Sweden (Skogaby). Plant Soil 221:273-280

Gavrichkova O, Kuzyakov Y (2010) Respiration costs associated with nitrate reduction as estimated by ${ }^{14} \mathrm{CO} 2$ pulse labeling of corn at various growth stages. Plant Soil 329:433-445

Gessler A, Scherempp S, Matzarakis A, Mayer A, Rennenberg H, Adams MA (2001) Radiation modifies the effect of water availability on the carbon isotope composition of beech (Fagus sylvatica). New Phytol 150:653-664
Göttlicher A, Knohl A, Wanek W, Buchmann N, Richter A (2006) Short-term changes in carbon isotope composition of soluble carbohydrates and starch: from canopy leaves to the root system. Rapid Commun Mass Spectrom 20:653660

Grimmer C, Komor E (1999) Assimilate export by leaves of Ricinus communis L. growing under normal and elevated carbon dioxide concentrations: the same rate during the day, a different rate at night. Planta 209:275-281

Grodzinski B, Jiao J, Leonardos ED (1998) Estimating photosynthesis and concurrevt export rates in $\mathrm{C} 3$ and $\mathrm{C} 4$ species at ambient and elevated $\mathrm{CO}_{2}$. Plant Physiol 117:207-215

Hartley IP, Armstrong AF, Murthy R, Barron-Gafford G, Ineson $\mathrm{P}$, Atkin OK (2006) The dependence of respiration on photosynthetic substrate supply and temperature: integrating leaf, soil and ecosystem measurements. Glob Change Biol 12:1954-1968

Hölttä T, Mencuccini M, Nikinmaa E (2009) Linking phloem function to structure: analysis with a coupled xylemphloem transport model. J Theor Biol 259:325-337

Horwath WR, Pregitzer KS, Paul EA (1994) ${ }^{14} \mathrm{C}$ allocation in tree-soil systems. Tree Physiol 14:1163-1176

Irvine J, Law BE, Kurpius MR (2005) Coupling of gas exchange with root and rhizosphere respiration in a semiarid forest. Biogeochemistry 73:271-282

Kayler Z, Gessler A, Buchmann N (2010) What is the speed of link between aboveground and belowground processes? New Phytol 187:885-888

Keitel C, Adams MA, Holst T, Matzarakis A, Mayer H, Rennenberg H, Gessler A (2003) Carbon and oxygen isotope composition of organic compounds in the phloem sap provides a short-term measure for stomatal conductance of European beech (Fagus sylvatica L.). Plant Cell Environ 26:1157-1168

Komor E (2000) Source physiology and assimilate transport: the interaction of sucrose metabolism, starch storage and phloem export in source leaves and the effects on sugar status in phloem. Aust J Plant Physiol 27:497-505

Kuptz D, Fleischmann F, Matyssek R, Grams TEE (2011) Seasonal patterns of carbon allocation to respiratory pools in 60-yr-old deciduous (Fagus sylvatica) and evergreen (Picea abies) trees assessed via whole-tree stable carbon isotope labeling. New Phytol. doi:10.1111/j.1469-8137.2011.03676.x

Kuzyakov Y, Domanski G (2000) Carbon input by plants into the soil. Review. J Plant Nutr Soil Sci 163:421-431

Kuzyakov Y, Gavrichkova O (2010) Time lag between photosynthesis and carbon dioxide efflux from soil: a review of mechanisms and controls. Glob Change Biol 16:3386-3406

Mencuccini M, Hölttä T (2010a) The significance of phloem transport for the speed with which canopy photosynthesis and belowground respiration are linked. New Phytol 185:189-203

Mencuccini M, Hölttä T (2010b) On light bulbs and marbles. Transfer times and teleconnections in plant fluid transport systems. New Phytol 187:888-891

Nguyen C, Todorovic C, Robin C, Christophe A, Guckert A (1999) Continuous monitoring of rhizosphere respiration after labeling of plant shoots with ${ }^{14} \mathrm{CO}_{2}$. Plant Soil 212:191-201 
Peuke AD, Rokitta M, Zimmermann U, Schreiber L, Haase A (2001) Simultaneous measurements of water flow velocity and solute transport in xylem and phloem of adult plants of Ricinus communis over a daily time course by nuclear magnetic resonance spectrometry. Plant Cell Environ 24:491-503

Phillips RP, Fahey TJ (2005) Patterns of rhizosphere carbon flux in sugar maple (Acer saccharum) and yellow birch (Betula allegheniensis) samplings. Glob Change Biol 11:983-995

Plain C, Gerant D, Maillard P, Dannoura M, Dong YW, Zeller B, Priault P, Parent F, Epron D (2009) Tracing of recently assimilated carbon in respiration at high temporal resolution in the field with a tuneable diode laser absorption spectrometer after in situ ${ }^{13} \mathrm{CO}_{2}$ pulse labelling of 20 -yearold beech trees. Tree Physiol 29:1433-1445

Pumpanen JS, Heinonsalo J, Rasilo T, Hurme KR, Ilvesniemi H (2009) Carbon balance and allocation of assimilated $\mathrm{CO}_{2}$ in Scots pine, Norway spruce, and Silver birch seedlings determined with gas exchange measurements and ${ }^{14} \mathrm{C}$ pulse labelling. Trees 23:611-621
Scartazza A, Mata C, Matteucci G, Yakir D, Moscatello S, Brugnoli E (2004) Comparison of $\delta 13 \mathrm{C}$ of photosynthetic products and ecosystem respiration and their response to seasonal climate variability. Oecologia 140:340-351

Subke JA, Vallack HW, Magnusson T, Keel SG, Metcalfe DB, Högberg P, Ineson P (2009) Short-term dynamics of abiotic and biotic soil ${ }^{13} \mathrm{CO}_{2}$ effluxes after in situ ${ }^{13} \mathrm{CO}_{2}$ labelling of boreal pine forest. New Phytol 183:349-357

Van Bel AJE (2003) The phloem, a miracle of ingenuity. Plant Cell Environ 26:125-149

Werth M, Kuzyakov Y (2008) Determining root-derived carbon in soil respiration and microbial biomass using ${ }^{14} \mathrm{C}$ and ${ }^{13} \mathrm{C}$. Soil Biol Biochem 40:625-637

Wu Y, Tan H, Deng Y, Wu J, Xu X, Tang Y, Higashi T, Cui X (2010) Partitioning pattern of carbon flux in a Kobresia grassland on the Qinghai-Tibetan Plateau revealed by field ${ }^{13} \mathrm{C}$ pulse-labeling. Glob Change Biol 16:2322-2333

Zimmermann MH (1960) Transport in the phloem. Annu Rev Plant Physiol 11:167-190 